\title{
Adrenal crisis: a rare endocrine emergency with challenging diagnosis
}

\author{
Ankit Bhardwaj $^{1 *}$, Vivek Singh ${ }^{1}$, Kaveri Kapoor ${ }^{1}$, Anil Kem ${ }^{2}$
}

${ }^{1}$ Department of Pharmacology, ${ }^{2}$ Department of Medicine, Saraswathi Institute of Medical Sciences, Hapur, Uttar Pradesh, India

Received: 28 July 2020

Accepted: 01 September 2020

*Correspondence:

Dr. Ankit Bhardwaj,

Email: drankitbhardwaj25@gmail.com

Copyright: (C) the author(s), publisher and licensee Medip Academy. This is an open-access article distributed under the terms of the Creative Commons Attribution Non-Commercial License, which permits unrestricted non-commercial use, distribution, and reproduction in any medium, provided the original work is properly cited.

\begin{abstract}
Adrenal crisis is a rare life-threatening medical endocrine emergency with non-specific insidious symptoms and challenging diagnosis. An appropriate timely diagnosis and treatment can save life. Although most doctors are educated by "sick day rules," but are reluctant to start glucocorticoids, increase doses or switch to parental injections. Our case report highlights various aspect of adrenal crisis.
\end{abstract}

Keywords: Adrenal crisis, Endocrine emergency, Glucocorticoids

\section{INTRODUCTION}

Adrenal insufficiency and its deceiving appearance were originally described by Addison. ${ }^{1}$ Adrenal crisis also termed acute adrenal insufficiency is an acute lifethreatening condition with a mortality rate of $0.5 / 100$ patients/year. ${ }^{2}$ It is considered one of the endocrine emergencies with a challenging diagnosis precipitated by an internal or external process in the setting of known or unknown lack of production of the adrenal hormone cortisol, the major glucocorticoid. ${ }^{3}$ Early identification and prompt management can save the patient's life and impact survival. The clinicians should be able to differentiate between adrenal insufficiency and adrenal crisis since the adrenal crisis is fatal if left untreated. ${ }^{4}$ While this disease is well described, it is often difficult to recognize, and treatment initiation maybe delayed leading to notable morbidity and mortality. ${ }^{5}$

\section{CASE REPORT}

We report a unique case of 55 years old female known case of hypertension, diabetes mellitus, diabetic nephropathy with hypomagnesia, presented to an emergency in critical shock condition, shortness of breath, mild sternal pain, fatigue, restlessness, and sweating triggered post stressful event. On primary survey, airway, patent bilateral chest rises present, bilateral air entry equal, respiratory rate of $24 / \mathrm{min}, \mathrm{SPO}_{2}$ : $96 \%$ on room air. GCS, pupils $2 \mathrm{~mm}$ BERL, moving all four limbs, no external injuries noted. The neurologic examination revealed a confused mental status with slurring of speech and b/l proptosis. There was no focal neurological sign, pathologic reflex, and neck stiffness. Sluggish gastrointestinal movements, Peri pheries were cold and peripheral pulses well felt, CRT less than $2 \mathrm{sec}$, HR- 102/min, BP- 198/116 mm, Hg, and RBS-362 mg/dl.

Initial venous blood gas analysis showed metabolic acidosis (pH-7.18, BE-21 mmol/L, HCO3-8.9 mmol/l, lactate-1.42 $\mathrm{mmol} / \mathrm{L})$, potassium $(\mathrm{K}+5.5 \mathrm{mmol} / \mathrm{l})$ and hyponatremia $(\mathrm{Na}+123 \mathrm{mmol} / \mathrm{L})$, glucose $363 \mathrm{mmol} / \mathrm{l}$. Sr. calcium $8.6 \mathrm{mg} / \mathrm{dl}$ and sr. magnesium $1.6 \mathrm{meq} / \mathrm{l}$. MRI brain showed normal studies.

Treatment to correct these abnormalities she was given inj. labetalol $20 \mathrm{mg}$ and 1 unit of regular insulin i.m, but no changes recorded in B.P after 1 hour. Blood sugar level falls to $262 \mathrm{mg} / \mathrm{dl}$. A second dose of inj. labetalol 20 mg given and waited for another hour. No fall in b.p recorded. Considering the rare cause of refractory shock, she was given hydrocortisone $100 \mathrm{mg}$ on to cover the 
possibility of acute addisonian crisis followed which B.P come to $154 / 96 \mathrm{~mm} \mathrm{Hg}$. Blood sample collected and send to biochemistry and pathology lab for a routine blood examination. Investigations revealed mild anemia ( $\mathrm{Hb}$ : $10.3 \mathrm{~g} / \mathrm{dl}$ ), (TLC:11.5×109 1), Normal liver and renal function tests with hyponatremia $\left(\mathrm{Na}^{+}=124 \mathrm{mmol} / \mathrm{L}\right)$. Urine routine and microscopy were normal.

Patient transferred to the ward and kept under observation for 24 hours. Followed which patient discharged at a satisfactory note.

Medical history of interest: Patient is a known case of hypertension, diabetes mellitus, diabetic nephropathy, pulmonary embolism, and hypomagnesia from the last 10 years. Interestingly, the patient has also been admitted to the cardiology ICU because of similar clinical presentation 2.5 years back.

\section{DISCUSSION}

This case report highlights many important aspects of adrenal insufficiency and crisis. Above all, it illustrates the difficulty to recognize the non-specific insidious symptoms that often develop during several years and with repeated undiagnosed symptoms, result in suffering of the patient. The past medical history, symptoms and signs may have been present for many years, arthralgia, fatigue, and all the psychiatric disorders that notably did not improve by medication, were probably caused by primary adrenal insufficiency all along. The diagnosis of adrenal insufficiency is extremely challenging in the early stages and can even delude endocrinologists. Morning values of $\mathrm{S}$-cortisol levels may be normal and miss leading make a degree of suspicion unfortunately low at the time and may have led to insufficient consideration and careless, incorrect, discarding of the diagnosis adrenal insufficiency. This shows that the interpretation of S-cortisol is difficult and that adrenal insufficiency should not be ruled out with random values. ${ }^{6}$ Only higher values within the normal range generally exclude primary adrenal insufficiency $(>550 \mathrm{nmol} / \mathrm{L})$ and besides repeated evaluations, one should simultaneously measure Adrenocorticotropic hormone(ACTH), where a morning value of double the reference range's upper limit suggests adrenal insufficiency and thereto determines the cause as primary. ${ }^{7}$ Unless these results are unambiguous, it is recommended to confirm the diagnosis with the gold standard ACTH stimulation test. ${ }^{8}$ Current clinical guidelines propose that patients diagnosed with primary adrenal insufficiency should be evaluated for mineralocorticoid deficiency. However, in cases with an autoimmune origin, the zona glomerulosa is often affected first, with consequential increases in plasma renin activity and normal to low serum aldosterone levels then being the earliest signs of the disease. We, therefore, contemplate whether it may be advantageous to assess a possible mineralocorticoid deficiency already in initial stages of suspected primary adrenal insufficiency to earlier approach but note, not exclude the diagnosis. Certainly, our patient had long-standing signs and symptoms of mineralocorticoid deficiency presenting as electrolyte disturbances. Either way, it is unequivocal that we must raise our vigilance, more generously suspect adrenal insufficiency and allow our clinical judgment to guide us to a more meticulous evaluation of possible causes. Glucocorticoids secreted from the adrenal cortex are the major rate-limiting factor for epinephrine synthesis from the adrenal medulla. The intra-adrenal portal vascular system carries the corticosteroids directly to the adrenal medulla chromaffin cells. Thus, any stress that persists sufficiently to provoke the secretion of epinephrine result in regulation of B.P. ${ }^{9}$

Primary or secondary adrenal insufficiency is rare and uncommon and approximately $50 \%$ of all cases are first recognized when the patient eventually presents with a life-threatening adrenal crisis with a delayed or missed diagnosis. It is, therefore, important to suspect adrenal crisis in all acutely ill patients with cerebrovascular accidents and cardiovascular collapse. The therapeutic threshold should be low and parenteral administration of $100 \mathrm{mg}$ hydrocortisone should not be delayed awaiting diagnostic measures. ${ }^{10}$ Although recovery usually is quick and miraculous, improvement can sometimes withstand nearly a week, especially in cases where chronic adrenal insufficiency has gone undetected for a longer period of time and finally presents with an affected level of consciousness.

This is only one of many cases that depict the diagnostic struggle of the Addisonian crisis. It is frequently mistaken for cardiac, cerebrovascular accident, psychological disorder such as depression, apathy, anxiety or even psychosis, and already in the originally described cases by Addison it is obvious that these traits often precede other symptoms. ${ }^{11}$

\section{CONCLUSION}

All acutely ill patients who present with possible signs of adrenal crisis, such as cardiovascular collapse, cerebrovascular accidents should immediately be treated with $100 \mathrm{mg}$ hydrocortisone intravenously without considering their medical history. The therapeutic threshold for administering the life-saving drug should be low and not delayed by diagnostic measures. Suspect chronic adrenal insufficiency in patients with gradual onset of non-specific symptoms such as fatigue, postural dizziness, weight loss, gastrointestinal manifestations or psychiatric disorders. The condition should not be ruled out by a single cortisol measurement, instead, our clinical judgment should guide us to more dedicatedly re-evaluate suspected cases. In chronic known patient, disaster management kit with a brief instruction card for patient attendant and health caregiver should be prepared.

\section{Funding: No funding sources Conflict of interest: None declared Ethical approval: Not required}




\section{REFERENCES}

1. Addison T. On the constitutional and local effects of disease of the supura-renal capsules. Highley, London; 1855.

2. Hahner S. Acute adrenal crisis and mortality in adrenal insufficiency: still a concern in 2018! In Annales d'endocrinologie. Elsev Mass. 2018;79(3):164-6.

3. Higham CE, Olsson-Brown A, Carroll P, Cooksley T, Larkin J, Lorigan P, et al. Society for Endocrinology Clinical Committee. Society for endocrinology endocrine emergency guidance: Acute management of the endocrine complications of checkpoint inhibitor therapy. Endocr Connect. 2018;(7):G1-7.

4. Betterle C, Presotto F, Furmaniak J. Epidemiology, pathogenesis, and diagnosis of Addison's disease in adults. J Endocrinol Invest. 2019;42(12):1407-33.

5. Husebye ES, Allolio B, Arlt W, Badenhoop K, Bensing S, Betterle C, et al. Consensus statement on the diagnosis, treatment and follow-up of patients with primary adrenal insufficiency. J Intern Med. 2014;275(2):104-15.

6. Elsevier Point of Care. Primary adrenal insufficiency, clinical overview. Available at: https://www.clini calkey.com/\#!/content/67-s2.0-74c5f862-11e4-4bfdabe8-8409af9fe071. Accessed on 27 July 2020.
7. Charmandari E, Nicolaides NC, Chrousos GP. Adrenal insufficiency. Lanc. 2014;383(9935): 2152-67.

8. Amrein K, Martucci G, Hahner S. Understanding adrenal crisis. Intensive Care Med. 2018;44:652-5.

9. Brunton LL, Hilal R, Knollmann BC. Goodman \& Gilman's the pharmacological basis of therapeutics. 13th edition. 2018; 130-40.

10. Nieman LK, Lacroix A, Martin K. Clinical manifestations of adrenal insufficiency in adults. Retrieved March. 2018. Available at: https://www.uptodate.com/contents/clinicalmanifestations-of-adrenal-insufficiency-in-adults. Accessed on $14^{\text {th }}$ July 2020.

11. Walsh J, Gittoes N, Selby P. Society for Endocrinology Clinical Committee. Society for Endocrinology Endocrine Emergency Guidance: emergency management of acute hypercalcaemia in adult patients. Endocr Connect. 2016;5:G9-11.

Cite this article as: Bhardwaj A, Singh V, Kapoor $\mathrm{K}, \mathrm{Kem} \mathrm{A}$. Adrenal crisis: a rare endocrine emergency with challenging diagnosis. Int J Basic Clin Pharmacol 2020;9:1612-4. 